\title{
Husserl on symbolic technologies and meaning-constitution: A critical inquiry
}

\author{
Dr Peter Woelert \\ Melbourne Graduate School of Education \\ University of Melbourne, Parkville 3010, Australia \\ Email: pwoelert@unimelb.edu.au
}

\begin{abstract}
:
This paper reconstructs and critically analyzes Husserl's philosophical engagement with symbolic technologies - those material artifacts and cultural devices that serve to aid, structure and guide processes of thinking. Identifying and exploring a range of tensions in Husserl's conception of symbolic technologies, I argue that this conception is limited in several ways, and particularly with regard to the task of accounting for the more constructive role these technologies play in processes of meaning-constitution. At the same time, this paper shows that a critical examination of Husserl's account of symbolic technologies, particularly as developed in his mature, genetic phenomenology, can be enduringly fruitful - if some of the specific conceptual weakness of this account are identified and properly accounted for. My discussion will proceed as follows. In the first part I briefly analyze the early Husserl's account of the role the 'method of sensible signs' plays in arithmetic cognition. In the second, main part I critically examine the bearing the genetic-phenomenological concepts of sedimentation and technization have on the conceptualization of symbolic technologies in Husserl's work. In the final part I summarize the major strengths and weaknesses of Husserl's account of symbolic technologies, and in the process make a case for the ongoing relevance of some of the crucial elements of this account.
\end{abstract}

\section{Keywords:}

Husserl; Symbolic Technology; Meaning-Constitution; Sedimentation; Genetic Phenomenology; Writing; Cultural Device; Cognitive Artifact 


\section{1) Introduction}

This paper reconstructs and critically analyzes Husserl's philosophical engagement with those material artifacts that are designed and employed to aid, structure, and guide processes of thinking. These artifacts, which can also be referred to as symbolic technologies, comprise longestablished cultural devices such as pictures, diagrams and writing systems (including mathematical notations) with cognitively efficacious representational, communicative or storage capacities. ${ }^{1}$ They also include more recent and technologically complex devices such as our modern computers that are capable of dynamically visualizing and processing information.

A serious and informed reflection on symbolic technologies and their manifold implications, epistemic and otherwise, undoubtedly constitutes a central task for contemporary philosophy, given not only the ubiquity of these devices in in our everyday cognitive lives, but also their apparently ever-increasing technological efficacy in storing, processing and representing information..$^{2}$ To this end, this paper endeavors to show, a critical reexamination of Husserl's phenomenological philosophy and of its mature, genetic variant in particular can be enduringly fruitful - if some of its specific conceptual weakness are identified and properly accounted for.

In devoting itself to the task of examining Husserl's philosophical engagement with symbolic technologies, this paper addresses a double gap in the philosophical literature: One existing in the rapidly growing philosophical literature on the cognitive dimensions of symbolic technologies, and one existing in the vast literature explicitly devoted to Husserl's phenomenology.

Repeated recourses to and comprehensive reflections upon the cognitive role of symbolic technologies feature prominently in many of the more recent philosophical attacks ${ }^{3}$ on the allegedly excessive representationalist and individualist tendencies in mainstream philosophy of mind and cognition. In in the context of many of these more recent discussions stressing variously - the 'extended', 'embedded', 'enactive' and 'embodied' nature of mind and cognition, the philosophical contributions of phenomenological thinkers such as Maurice Merleau-Ponty

\footnotetext{
${ }^{1}$ The term 'symbolic technologies' is derived here from the work of Merlin Donald, who defines symbolic technologies as those material cultural objects "that are specifically designed to represent, communicate and store knowledge" (2010, p. 71). A related and commonly used concept is that of 'cognitive artifacts' which refers to those "physical objects made by humans for the purpose of aiding, enhancing, or improving cognition" (Hutchins 2001, p. 126; see also Heersmink 2014).

2 See Floridi (2014).

3 E.g., Clark and Chalmers (1998), Rowlands (1999), Wheeler (2005); Menary (2007), Clark (2008).
} 
and Martin Heidegger have received considerable attention. ${ }^{4}$ Against this backdrop it is surprising that the dispersed (yet in sum, extensive) considerations by Edmund Husserl concerning symbolic technologies and their cognitive dimensions have been hardly taken into account in this literature.

But then again, this neglect may not come as a big surprise given that in the vast body of literature on Husserl's philosophy, there is a dearth of targeted investigations of Husserl's philosophical account of symbolic technologies. Similarly, relatively little effort has been made to date to properly evaluate Husserl's potential contributions to the philosophy of technology more broadly. 5 True, with regard to the issue of symbolic technologies at least, this issue is touched upon in a number of publications on Husserl's early writings on arithmetical cognition. ${ }^{6}$ And similarly, the issue of symbolic technologies is addressed in parts in a range of discussions of Husserl's later genetic-phenomenological writings on the constitution of ideal-objective meanings, 7 including the extensive treatment that one can find in Derrida's introductory essay to Husserl's Origin of Geometry. ${ }^{8}$ But it is fair to say that none of these discussions primarily devotes itself to the tasks of either investigating Husserl's philosophical account of symbolic technologies per se, or of evaluating its potential for the understanding of our contemporary symbolic-technological condition.

Addressing the resulting lacunae, this paper reconstructs and critically examines Husserl's conception of symbolic technologies. A particular focus is on the precise role that Husserl considers those technologies to play in processes of meaning-constitution, that is, in those cognitive processes (perceptual, linguistic, or otherwise) that allow for signification..$^{9}$ I identify a range of tensions running through Husserl's genetic-phenomenological account of meaningconstitution, and ultimately show that a case can be made for granting symbolic technologies a more constructive role in the constitution of meaning than Husserl envisioned. In line with my concern with symbolic-technological dimensions of meaning-constitution, my major focus of analysis is on Husserl's later, genetic phenomenological writings. In addition, I also briefly rehearse Husserl's earlier writings on arithmetic cognition. These not only contain Husserl's

\footnotetext{
4 See, e.g., Rowlands (1999); Wheeler (2005).

5 Kelly (2005).

6 E.g., Miller (1982), Willard (1984); Tieszen (1989), Hopkins (2002a); Ierna (2003); da Silva (2010).

7 E.g., Klein (1940); Blumenberg (1981); Rang (1989); Buckley (1991); Woelert (2013); Duke \& Woelert (2016).

8 Derrida (1978).

9 Zahavi (2003, p. 73); and comprehensively Solokowski (1964).
} 
most concrete analyses of symbolic technologies, but also anticipate important conceptions of symbolic-technological phenomena more fully developed in Husserl's genetic phenomenology. My discussion will proceed as follows. In the first part I explore the early Husserl's account of the use of the "method of sensible signs" in arithmetic cognition (section 2).10 In the second, main part of this paper I critically examine the genetic-phenomenological concepts of sedimentation and technization, their bearing on the issue of symbolic technologies, and the case that can be made for the genuinely constructive dimensions of symbolic technological practices (section 3). In the final part I present what I perceive to be the major strengths and weaknesses of Husserl's account of symbolic technologies, and in the process make a case for the ongoing relevance of some of the crucial elements of this account (section 4).

${ }^{10}$ Husserl (2003, p. 272). 


\section{2) The early Husserl on symbolic technologies: The method of sensible signs}

At first glance, philosophical inquiry into the epistemic nature and constitutive dimensions of symbolic technologies may not be one of the most conspicuous themes in Husserl's phenomenology. This said, it is striking that in both Husserl's earliest writings as well as in his late, genetic-phenomenological writings discussions of symbolic technologies feature prominently.

This applies first and foremost to Husserl's first book originally published in 1891, the Philosophy of Arithmetic (referred to as PA hereafter). In the PA, Husserl embarks on the project of a philosophical analysis of the concept of number, with the aim to clarify, by way of this analysis, the foundations of our higher-level mathematics. It is in the context of this inquiry that Husserl establishes, among other things, the important distinction between authentic and nonauthentic symbolic number concepts, or as Husserl puts it in the original German, between the concepts of Anzahl and Zahl.11

For Husserl, authentic numbers (Anzahlen) are constituted through the enumeration of concrete objects of intentional experience, where the associated number concepts can be grasped on the basis of a human individual's own intuitive capacities. This explains why the domain of authentic numbers, as being linked to an intuitable collectivity of objects, is for Husserl rather small, ranging from two ${ }^{12}$ up to around twelve. ${ }^{13}$ It is generally agreed upon in the literature that Husserl regards such Anzahlen as numbers "in the most basic sense of the word", existing 'prior' to any more abstract, "derivative senses of number."14 By contrast, symbolic (uneigentlich) numbers or Zahlen stand in for such countable objects if any form of intuitive comprehension is no longer possible. This is vital when the associated number concepts go beyond the intuitive grasp of the human mind and this mind's own "representational

11 See, e.g., Husserl (2003, pp. 200-203). Further, instructive discussions of this distinction and its potential merits and problems can be found in Miller (1982), Willard (1984), Tieszen (1989), Hopkins (2002a) and Ierna (2003). There have been extensive debates concerning the ways and extent to which Husserl's PA commits to the fallacy of psychologism - the failure to distinguish between subjective psychological experiences and the objective meaning-content that is instantiated in such experiences (see for recent, comprehensive discussions, e.g., Hopkins (2011) and Tieszen (2005)). These debates will not be rehearsed here, but as will be touched upon in section 3, Husserl in his more mature writings on the constitution of ideal objects clearly does not commit to any form of psychologism.

12 Husserl (2003, p. 138).

13 Husserl (2003, p. 202).

14 Miller (1982, p. 33). 
capacities."15 For example, while the basic number concept 'four' can be easily and precisely grasped by the human mind without any mediation by symbolic representations, the same cannot be said about the number concept of, say, '11,938'.

Due to the inherent cognitive limitations of the human mind, for Husserl the development of arithmetic necessarily involves the conceptual shift from the authentic numbers (Anzahlen), considered as being linked to the actual or potential objects of intuition, to symbolic numbers (Zahlen). This applies first of all to development of arithmetic as a "symbolic technique"16 and ultimately also to the advanced development of arithmetic as a formal-theoretical science. For Husserl, what distinguishes arithmetic as a formal-theoretical science from its more profane, applied variants is that the epistemic concern is no longer with particular applications of counting but rather with formal properties of numbers considered as a system of objects from a theoretical perspective.

For the early Husserl, our access to Zahlen - and by extension, the development of any more sophisticated theoretic form of arithmetic - is necessarily mediated by the systematic use of symbols. Moreover, these cannot be any symbols but, Husserl points out, must be written symbols with specific material and visual-spatial properties, the reasoning being that these written symbols (and their manipulation) facilitate what Husserl refers to in the PA as the "method of sensible signs", a method which he considers to be "the logical method of arithmetic." 17 In the case of arithmetic, Husserl specifies, this method comprises "any symbolic derivation of numbers from numbers that is substantively based on rule-governed operations with sense perceptible signs." 18 The "method of sensible signs" is considered by Husserl to be "the logical method of arithmetic" due to the fact that the systematic use of written numerical symbols offers a vastly superior degree of support to the counting and calculating human mind, particularly if compared to the use of those linguistic expressions of numbers that do not

\footnotetext{
${ }^{15}$ Husserl (2003, p. 202).

16 Husserl (2003, p. 161).

${ }^{17}$ Husserl (2003, p. 272). That Husserl regarded the development and use of written symbols as essential for the development of a more sophisticated form of arithmetic is also highlighted by the following passage: "We will soon see that the distinction between oral and written signs is so essential for arithmetic that an inescapable restriction to the former would have made a development of arithmetic on a larger scale impossible" (Husserl 2003, p. 257).

${ }^{18}$ Husserl (2003, pp. 272-273).
} 
involve any visual-spatial materialization. ${ }^{19}$ Husserl identifies three phenomenological aspects of such symbols and their use that facilitate their superior cognitive efficacy.

First, Husserl observes that these written numerical symbols (and the combinations of a variety of such symbols), due to their distinctively visual-spatial properties, are considerably easier to comprehend "at one glance" than are number words - particularly if the numbers in question are rather large. ${ }^{20}$ As Husserl recognizes, this is particularly the case if the written symbols are spatially arranged in a systematic manner, as in the Hindu-Arabic notation system where the "perceptual linear order" is effectively utilized "as the systematic means for designating the order of the power terms." 21

Second, Husserl notes that written numerical symbols "can be enduringly fixed for numbers" in a stable and reliable way that is "remarkably superior" to the use of number words. ${ }^{22}$ This superiority, Husserl suggests, is due to the fact that "a written symbol stands fast and can be newly grasped at any moment", while with a "very complicated number word, (...) we are immediately in danger of forgetting it again." 23

Third, Husserl observes that written symbols are considerably easier to manipulate in a reliable and rule-based manner than are their equivalents in speech. For Husserl, this makes them a vastly superior means for calculation, as in many instances the solution to an arithmetic problem "can be obtained in a purely mechanical fashion." 24 This occurs through a "pure calculational mechanism" that is based on the rule-based manipulation of signs, 25 in which "one derives sign from sign according to fixed rules." ${ }^{26}$ Husserl apparently even deliberates over whether the system of written number symbols may have played some sort of constructive role in facilitating the systematization of the rules of arithmetic operations in first place ${ }^{27}$ - yet

\footnotetext{
${ }^{19}$ Husserl (2003, pp. 257-258). Husserl elaborates as follows: "The best signs, therefore, are written signs that are easily fixed, are formed to have the greatest possible capacity for comprehension in one glance, and at the same time are the shortest and most distinct ones possible" (Husserl 2003, p. 258).

${ }^{20}$ Husserl (2003, p. 257).

${ }^{21}$ Husserl (2003, p. 258).

${ }^{22}$ Husserl (2003, p. 257; my emphasis).

${ }^{23}$ Husserl (2003, p. 257).

${ }^{24}$ Husserl (2003, p. 253).

${ }^{25}$ Husserl (2003, p. 274).

${ }^{26}$ Husserl (2003, p. 272).

${ }^{27}$ See Husserl (2003, pp. 271-273).
} 
ultimately, the more prominent position he maintains in the PA is that all such rules have their roots in "[r]eflections on concepts." 28

It remains one of the shortcomings of Husserl's discussions presented in the PA that the role that such material numerical symbols play in the constitution of abstract mathematical meanings is not systematically addressed. This fact may however not be surprising given that Husserl, when writing the PA, did not yet have a explicitly developed, phenomenological concept of meaning-constitution (and with it an account of intentionality) at his disposal despite the fact that he later explicitly referred to this earliest work as "a phenomenological constitutional study." 29 This said, the PA contains a range of interesting indications for how Husserl could have envisioned such constitutive role, all of which point to a range of related yet ultimately conflicting conceptions:

\section{1) Mathematical symbols as tools for conceptual extension}

In the PA, Husserl occasionally argues that the systematic use of the aforementioned "method of sensible signs" by human agents facilitates an extension of more basic forms of arithmetical thinking and its number concepts. More specifically, Husserl suggests that the use of written, mathematical symbols is crucial in that it facilitates a vast expansion of the domain of number concepts available to the human mind, beyond the limited domain of those authentic numbers (Anzahlen) that this mind can grasp intuitively. Importantly, however, and despite his fundamental recognition that "Arithmetic Does Not Operate with 'Authentic Number Concepts',"30 Husserl at various occasions throughout the PA refers to the relation between the "system of concepts and that of signs" in terms of a "parallelism,"31 and, more precisely, a "rigorous parallelism."32 This would indicate a view according to which the exterior, sensible signs utilized in arithmetical practice are understood to function primarily as accompaniments of (nonsignitive) number concepts, without really attaining a degree of independence from them, and

\footnotetext{
${ }^{28}$ Husserl (2003, p. 256). Such a systematization of rules, one may add in broad reference to Husserl's more mature texts such as the Logical Investigations and also the Crisis, is considerably easier to come by if the material symbols employed are both graphically and semantically emptied from any intuitive associations and meanings, that is, where there is "a contingent, external relation between matter and representative content" (Husserl 1970c, p. 26).

${ }^{29}$ Solokowski (1964, p. 6).

${ }^{30}$ Husserl (2003, p. 200).

${ }^{31}$ Husserl (2003, p. 254).

32 Husserl (2003, p. 255; also p. 251).
} 
more importantly, without themselves fulfilling a genuinely originary constitutive role concerning number concepts and arithmetical cognition more broadly.

\section{2) Mathematical symbols as constitutive tools}

At other times in the PA, Husserl gestures toward a conception according to which the "method of sensible signs" plays a sui generis constructive role in the constitution of arithmetic thought. One indication for this kind of radical view - which is not, however, systematically developed throughout the PA - can be found in a passage in which Husserl asserts that that the 'sensible signs' involved in the process of the formation of Zahlen are more than "mere accompaniments of concepts" and ultimately "participate in a far more striking manner in our symbolic formations than we have validated to this point." 33 Also, given Husserl's insight that "all number representations [Zahlvorstellungen] that we possess, beyond the first few in the number series, are symbolic, and can only be symbolic," 34 all this would indicate a much more prominent role for 'sensible' signs than can be subsumed under the notion of these signs facilitating merely some sort of direct, conceptually controlled extension of 'authentic' number concepts. ${ }^{35}$ The same can also be said with regard to Husserl's observation that these external, material signs ultimately may attain a roundly dominating position in our arithmetical endeavors, ${ }^{36}$ even at the level of "small numbers (...) where the conceptual content could still be brought before the mind." 37 This leads me to the third strand of thinking about the constitutive status of symbolic technologies that can be identified in the PA.

\section{3) Mathematical symbols as surrogates for conceptual thinking}

A reoccurring theme in the PA is that in arithmetical practice, the (technical manipulation of) sensible signs may substitute for number concepts altogether, thus giving way to "a mainly nonconceptual manipulation of sensible signs." ${ }^{38}$ Husserl sees the roots of such a substitution in a 'breaking free' of the "mechanism of the symbolic methodology (...) of the conceptual substrate of its employment." 39 This breaking free has in turn primarily practical grounds. Compared to the method of concepts, which as Husserl notes is "highly abstract, limited, and, even with the most intensive practice, laborious", the method of sensible "signs is concrete, sense perceptible,

\footnotetext{
33 Husserl (2003, p. 255).

34 Husserl (2003, p. 200; my insertion).

35 See on this point also Hopkins (2002a).

${ }^{36}$ Husserl (2003, p. 255).

${ }^{37}$ Husserl (2003, p. 256).

38 Willard (1984, p. 108).

${ }^{39}$ Husserl (2003, p. 273).
} 
all-inclusive, and it is, already with a modest degree of practice, convenient to work with." 40 This is to the point that once the 'method of sensible signs' has attained a certain level of proficiency, "all numbering and calculating could dispense with recourse to the underlying concepts." 41 Husserl concedes that this detachment of the manipulations of sensible signs from their conceptual correlates is acceptable if considered from a purely practical point of view. Yet at the same time, Husserl also points out that such detachment ultimately amounts to the substitution of a profane "calculational technique" or Rechenkunst for a more profound form of "arithmetical cognition." 42

To summarize, in Husserl's early work on arithmetical cognition one can find three varying, partially conflicting conceptions of the constitutive function of symbolic technologies in arithmetical cognition. These are, (1) the notion that material symbols allow for a conceptually controlled extension of more basic and intuition-based forms of mathematical thinking into more abstract domains; (2) the notion that such symbols are intrinsic to the constitution of more abstract mathematical conceptions in a way that dramatically exceeds any such extension; and (3) the notion that in mathematical practice the, as it were, mechanical manipulation of such symbols tends to substitute for mathematical concepts and conceptual thinking altogether.

\footnotetext{
${ }^{40}$ Husserl (2003, p. 272).

${ }^{41}$ Husserl (2003, p. 256).

${ }^{42}$ Husserl (2003, p. 274). It is this precisely this theme of a 'technization' and 'mechanization' of thought through symbolic technologies that Husserl returns to and further develops upon in his more mature works (see section 3.1).
} 


\section{3) The later Husserl on symbolic technologies: Sedimentation and technization}

Interestingly, similar tensions with regard to the conceptualization of the constitutive dimensions of symbolic technologies, in mathematical thinking and elsewhere, still exist in Husserl's late, genetic-phenomenological writings, notably in the Crisis (CR) and the Origin of Geometry (OG). However, these tensions can only be adequately grasped and reflected upon philosophically if one takes into account the significantly developed theoretical structure of Husserl's mature phenomenological philosophy.

Most importantly for the purpose of this paper, Husserl had in the meantime more explicitly focused his phenomenological-philosophical project on the problem of constitution; that is, on the exploration of the processes through which 'things' (ranging from directly intuitable physical bodies to abstract mathematical objects) attain their meaning for the human mind. ${ }^{43} \mathrm{As}$ part of this momentous shift Husserl had further developed his own phenomenological concept of intentionality - a concept reflecting the apparent peculiarity that individual consciousness, in its various cognitive and affective manifestations, is and remains phenomenologically always and essentially "consciousness of something." 44

Moreover, with regard to the exploration of the problem of constitution Husserl had moved to a genetic perspective when writing the $\mathrm{CR}$ and the $\mathrm{OG}$, in contrast to his earlier writings addressing the issue of constitution that are characterized by a static approach. ${ }^{45}$ Put briefly, what defines Husserl's analysis of static constitution is that it has "stable objects, a stable 'ontology' as its guide." 46 By contrast, in an analysis of genetic constitution, the major questions concern the ways in which these objects are constituted, dynamically and diachronically. Thus, as Bernet, Kern and Marbach stress, in Husserl's transition from static to genetic phenomenology the concept of constitution, in term of its direction of enquiry, undergoes a significant shift: "The object is no longer the guidepost as it is in static phenomenology. It is rather something that has come to be." 47

Another important change in Husserl's overall philosophy concerns his development of the conception of ideal objects. As Husserl recognizes in his more mature philosophical work, there

\footnotetext{
43 See comprehensively Solokowski (1964).

${ }^{44}$ Husserl (1982, p. 73).

45 See Bernet, Kern and Marbach (1993, pp. 195-204); Solokowski (1964).

46 Bernet, Kern and Marbach (1993, p. 196).

47 Bernet, Kern and Marbach (1993, p. 201).
} 
are certain intentional objects, like numbers and geometrical shapes, which, once properly constituted, attain an "ideal' objectivity'." 48 Such ideal objectivity entails at least two things for Husserl. First, the intended objects in question are "supertemporal," that is, they always remain the same regardless of the particular historical contexts (and concrete situations) in which they are intended. ${ }^{49}$ Second, and clearly departing from any sort of psychologism, Husserl stresses that objects that have attained the status of ideal objectivity "do not exist as something personal within the personal sphere of consciousness" but rather are "objectively there for 'everyone"' that is, they are exactly the same objects accessible by all minds. 50

Consequently, when Husserl in his more mature works considers the status of ideal objects from the phenomenological perspective of meaning-constitution, he aims to give proper due to the constitutive role played by intentional consciousness, while at the same time upholding a qualified notion of such objects' objectivity. ${ }^{51}$ The same can be said with regard to the task of exploring the genetic constitution of ideal objects - with one difference being that Husserl, in his later writings, came to seriously consider the role that symbolic technologies and the associated processes of a sedimentation (and reactivation) of meanings play in the constitution of these sorts of objects. ${ }^{52}$

\section{$\underline{3.1 \text { Sedimentation and technization }}$}

In his later genetic-phenomenological deliberations on ideal objects, Husserl's discussions of symbolic technologies mainly concern the role that these technologies - most of all the technology of writing - play in what he refers to as the "internal history" 53 of scientific rationality; that is, in the history of the genesis and formation of this rationality's inner sense (which at its core includes that of the sense of ideal objects). Husserl conceives of that internal history primarily in terms of what has been characterized as a "transcendental-immanent history". ${ }^{54}$ This sort of history is distinguished for Husserl by virtue of its being grounded in one

\footnotetext{
${ }^{48}$ Husserl (1970b, p. 356).

${ }^{49}$ See Husserl (1970b, pp. 356-357).

${ }^{50}$ Husserl (1970b, p. 356). 1969, p. 263; see on this point also Hartimo 2012; Tieszen 2010).

${ }^{52}$ See Duke and Woelert (2016).

${ }^{53}$ Husserl (1970b, p. 378).

${ }^{54}$ Ströker (1993, p. 185).
}

${ }^{51}$ In Husserl's own words, the particular task of a phenomenological theory of constitution is to consider "ideal formations (...) as essentially products of the correlative structures of productive cognitive life" without that the "ideal Objectivity" of those formations would be compromised in the process (Husserl 
"universal historical a priori" as well as held together by "a universal teleology of reason". ${ }^{55}$ As such, the 'internal' history of scientific rationality is to be strictly delineated from an 'external' history comprising externally related empirical facts and factual historical constellations. ${ }^{56}$ Given this idealizing conception of 'internal history', Husserl's repeated allusions to the technology of writing and its material dimensions may indeed appear surprising, even problematic - to the point that one may wonder they point to a fundamental difficulty in the separation of internal from external history per se. I will return to this point at a later stage (section 3.2).

In his reflections on internal history, the issue of symbolic technologies enters the picture mainly through Husserl's conceptualization of what he refers to as processes of a sedimentation of meaning (see further below). For Husserl, such processes of sedimentation form a crucial part of the dynamics of internal history, together with the "original formations" of meaning, with which, Husserl proposes, the former co-exist and with which they are interwoven. ${ }^{57}$ Entailed by this understanding of internal history is the notion that the unfolding of this history involves the building up of various layers of sedimented meanings, as a result of which the original formations of meaning, while still remaining somehow 'active', are at least partially superimposed. The idea that our formations of meanings have a "sedimented history"58 in turn circumscribes the aim and scope of the genetic-phenomenological enquiry into internal history: Starting from a given formation of meaning, this enquiry is primarily oriented toward the uncovering of the preceding, sedimented layers of meaning that underpin this formation, and eventually back to this formation's constitutive origins. With specific regard to the internal history of modern scientific rationality, this explains Husserl's conviction that that this history can be traced, as Ströker puts it, by working "through the manifold layers of sense of scientific formations" 59 back to what Husserl regards as the ultimate "meaning-fundament", namely the human life-world.60

\footnotetext{
55 Husserl (1970b, p. 378).

${ }^{56}$ See Husserl (1970b, p. 378). For a further discussion of Husserl's concept of 'internal history' and the context of its conceptual development within Husserl's work more specifically see Ströker (1993, pp. 175197).

${ }^{57}$ Husserl (1970b, p. 371). In Husserl's own words, internal history is the "vital movement of the coexistence [Miteinander] and the interweaving [Ineinander] of the original formations and sedimentations of meaning" (Husserl 1970b, p. 371, translation modification; my insertion).

${ }^{58}$ Husserl (1969, p. 245).

${ }^{59}$ Ströker (1993, p. 184).

${ }^{60}$ Husserl (1970a, p. 49).
} 
What specifically, then, does Husserl mean when he speaks of sedimentation, and how does this relate to the issue of symbolic technologies? As indicated above, when Husserl in his later writings speaks of 'sedimentation' he usually refers to a process of the consolidation of meanings which eventually involves their stratification. As a matter of fact, phenomenological scrutiny reveals that processes of sedimentation occur on various levels of semiotic activity, including the more basic levels where the human agent's own body directly functions as semiotic agent. ${ }^{61}$ In Husserl's OG, however, the explicit focus is on those linguistically mediated processes of consolidation of meanings as a result of which, Husserl suggests, the more basic layers of meaning-constitution, which have their base in individual perceptual-intuitive activity, are progressively superimposed upon by "persisting linguistic acquisitions."62 More specifically, a particular emphasis is placed on the form of sedimentation that occurs with and through the use of the medium of writing - for reasons that will be developed upon further in the following.

Mirroring his account presented in the PA, Husserl observes that writing is peculiar as a linguistic medium by virtue of the fact that it allows for the "sensible embodiment" 63 of meanings through a generalized system of signs in which the signs are "sensibly experienceable" by one's visual senses, and are importantly of such a disposition that they are potentially "intersubjectively experienceable in common." ${ }^{4}$ Furthermore, Husserl notes that these signs and the meanings they carry - by virtue of their material embodiment - are capable of a more enduring form of existence to the point that they can outlast the existence of their living creators. ${ }^{65}$ According to Husserl's account, there are a number of implications stemming from these features of writing.

First, Husserl appears to suggest that the manifest stabilization occurring on the level of the meaning carriers (i.e., the material, written signs) stimulates, along with one's increasing familiarity with written words, a conceptually efficacious process of a stratification and consolidation of once actively constituted meanings - namely the process of sedimentation referred to above. By virtue of this latter process, the symbolically embodied concepts turn into readily available and practical tools for one's own thought. But, Husserl claims, the same process also means that the genetic dimensions of such concepts and the conditions of the

\footnotetext{
${ }^{61}$ See Woelert (2011).

${ }^{62}$ Husserl (1970b, p. 362).

${ }^{63}$ Husserl (1970a, p. 26).

${ }^{64}$ Husserl (1970b, p. 361).

${ }^{65}$ See Husserl (1970b, p. 360).
} 
originary constitution of their meaning tend to become lost out of sight and forgotten (see, e.g., Husserl 1970b, 361). In short, Husserl claims that writing fosters the sedimentation of meanings that can be readily reactivated at later stages through the reading of signs, but for the most part in a way where "the awakened signification is (...) given passively." 66 Owing to this apparent propensity toward forgetfulness and passivity, Husserl does not cease to regard linguistic mediation and the associated processes of sedimentation, despite all their practicalities, as posing a "constant danger" to any form of thought; particularly rational-philosophical thought which strives for the highest degree of lucidity and self-evidence. ${ }^{67}$ As Klein sums up Husserl's view, "a kind of superficial and 'passive' understanding is the necessary result of the increasing familiarity with spoken and written words."68

Second, Husserl points out that the medium of writing makes it possible - by virtue of its temporally enduring, material embodiment of meanings - for meanings to be communicated effectively "without immediate or mediate personal address." ${ }^{69}$ Husserl also speaks of the fact that through writing, communication attains a "virtual" dimension, that is, it emancipates itself from the interaction of subjects in the living present, thus allowing for the constitution of a totally new, expanded form of community. ${ }^{70}$ Importantly, this emancipation means that meanings can be reactivated, repeatedly if necessary, by a plurality of human agents, even if these agents are spatially and temporally removed from the situation of the agent who first of all expressed them, thus leading to an 'objectification' of the sedimented meaning-contents. Husserl repeatedly stresses that he considers this possibility of the reactivation of sedimented meanings to be crucial, particularly as concerns the constitution of ideal objects ${ }^{71}$ - this is despite his aforementioned insistence that such reactivation is first and foremost one of passivity. I will return to this point in the following section.

In his genetic-phenomenological writings, Husserl further introduces the concept of 'technization' referring to a specific type of sedimentation occurring in more abstract, formal

\footnotetext{
${ }^{66}$ Husserl (1970b, p. 361). Notably, Husserl does not rule out the possibility that at least occasionally, reactivation can also occur in such a way that brings back to light the original meanings and the activity that constituted them (Husserl 1970b, p. 361). But overall Husserl regards such more 'active' reactivation as the exception rather than the rule.

${ }^{67}$ Husserl (1970b, p. 362).

${ }^{68}$ Klein (1940, p. 155).

${ }^{69}$ Husserl (1970b, pp. 360-361).

${ }^{70}$ Husserl (1970b, p. 361); see on this specific point also Derrida (1978, p. 87).

${ }^{71}$ E.g., Husserl 1970b (pp. 358-361).
} 
modes of rational thinking. ${ }^{72}$ Importantly, however, this does not mean that Husserl regards formalization and technization as being one and the same. On the most basic level, formalization can be conceived of as a symbol-based method or technique enabling decontextualized, schematic descriptions of a wide range of processes, in rigid abstraction from any concrete referents and situations. ${ }^{73}$ This sort of abstraction, Husserl notes, means that the procedure of formalization entails a significant change to the 'meanings' one operates with in rational thinking: These are no longer recognizable as the products of concrete, intentional-intuitive activity, but ultimately attain the form "of the 'something-in-general' which can be constructed in pure thought and in empty, formal generality." 74 By contrast, technization is understood to be one of formalization's potential after-effects. More specifically, Husserl's concept of technization designates a transformation of the practice of rational thinking as a result of which this thinking, along with the increasing reliance on formal methods, becomes more efficient and effortless. This, Husserl notes, is to the point that rational thought itself "becomes a sort of technique", namely, a "calculating technique."75 It is however precisely this cognitively alleviating process of technization that entails for Husserl that thought - technized rational thought - tends to become somewhat mechanical and forgetful, and thus ultimately, as Buckley comments, more "thoughtless."76

Husserl's position as to what is at the root of this apparent propensity toward 'technization' is not entirely clear-cut. Obstructing the overall picture is a reoccurring 'idealizing' tendency in Husserl's later writings: A tendency to regard the process of technization primarily in

\footnotetext{
${ }^{72}$ This said, considerations thematically related to what Husserl later on would label 'technization' feature already in his earlier and earliest work including the Logical Investigations and - as previously illustrated - the PA. In the Logical Investigations, Husserl takes issue with the notion of 'thoughteconomies' - initially put forward by Richard Avenarius and Ernst Mach - and in a way that anticipates his later conception of technization (Husserl 1970c, chapter 9). 'Thought-economies' for Husserl are prone to the mechanical use and application of methods, most of all of those (formal) methods "which are rendered secure because a general proof of the efficiency of the method has been once and for all guaranteed" (Husserl 1970c, p. 201).

${ }^{73}$ See Krämer (1988, pp. 1-3).

${ }^{74}$ Husserl (1970a, p. 45).

${ }^{75}$ Husserl (1970a, p. 46). One should note that Husserl resorts here to almost the same terminology already employed in the PA- a further indication that, in many respects, Husserl's later, genetic reflections on symbolic technologies build directly onto those that one can find developed in his earliest writings.

76 Buckley (1992, p. 91).
} 
immanent-theoretical terms ${ }^{77}$ - and related to this, to regard the formation of rational-scientific thought as being primarily based in "idealizing, spiritual act, one of 'pure' thinking."78 Then again, Husserl in his later writings also repeatedly makes allusions to the hypothesis that this propensity has its major source in the fact that the formal method has itself attained, and necessarily so, a manifestly technical character.

It is important to note in this context that any formal description is first of all made possible through the use of a limited set of material symbols, where these symbols are manipulated according to explicit and well-defined rules. Viewed in this light, one may regard formalization at once as an epistemic process and a symbolic-technological practice. This reliance on rulebased symbolic-technological operations is also stressed by Husserl, who observes that in formal thinking one essentially "operates with letters and with signs for connections and relations" in strict accordance with "the rules of the games for arranging them together."79 Husserl concedes that this concrete 'technization' of method, qua the rule-governed, technical manipulation of symbols, bestows a remarkable degree of technical efficiency and reliability on rational thinking. ${ }^{80}$ Yet at the same time, he also sees the specific danger that one can relatively easily attain technical competence in the use of the formal method - that is, in the practices and rules of processes of symbol-manipulation - without attaining a deeper understanding of what first of all gave meaning to this method, of the specific symbolic conception of number that is associated with it, ${ }^{81}$ and of the sense of truth that this method bestows. ${ }^{82}$ This, Husserl warns, may be to the ultimate effect that rational thought itself in its functioning turns into some sort of

\footnotetext{
${ }^{77}$ See Blumenberg (1981, p. 28).

${ }^{78}$ Husserl (1970b, p. 377).

${ }^{79}$ Husserl (1970a, p. 46).

${ }^{80}$ See Husserl (1970a, p. 43; pp. 46-47).

${ }^{81}$ Characteristic of a symbolic conception of number is for Husserl an understanding of number as an abstract multiplicity. What made such understanding possible, Husserl contends, is a process in which numbers, qua their symbolic form, are 'displaced' from the original contexts that gave meaning to them, where all that is remembered in the end is that "the numbers signify magnitudes" (Husserl 1970a, p. 44). In his CR, Husserl refers to Descartes' algebraization of geometry as the paradigmatic case of such a displacement. The conceptual shifts that have led to the modern development (and, as it were, reification) of a symbolic conception of number have also been explored, with great historical sophistication, by Jacob Klein (1968). For a recent, both seminal and comprehensive discussion of the relationship between Klein's and Husserl's work see Hopkins (2011).

${ }^{82}$ Husserl (1970a, p. 46).
} 
"machine" - a very useful machine for sure - but also one that tends to be used without any proper reflection on, and insight into, its own constitution. ${ }^{83}$

\subsection{The constructive dimensions of symbolic technologies}

In spite of all its promising lines of inquiry, and in spite of all the advances made with regard to the formulation of a phenomenological theory of (genetic) constitution, the later Husserl's philosophical stance concerning symbolic technologies remains limiting in some of its aspects. It is in parts also contradictory (see section 4).

One major limitation concerns the mature Husserl's preoccupation with the negative dimensions of symbolic technological practices, and more specifically, with the associated processes of sedimentation and technization. In Husserl's mature works, the question concerning "the constitutive function of the method of sensible signs" remains by and large overshadowed by concerns regarding the 'danger' stemming from reliance on this method, as Rang correctly points out. ${ }^{84}$ The same can be said with regard to the question concerning the constructive, positive function of processes of sedimentation, which remains somewhat suppressed in Husserl's later writings. Furthermore, and as illustrated in more detail elsewhere, 85 in his genetic-phenomenological writings Husserl does not properly distinguish between different types of symbolic technologies (e.g., representations of geometrical figures, diagrams, different types of notations, etc.) and their respective contribution to the genetic constitution of ideal objectivity. This lack of a more detailed perspective may have contributed to Husserl neglecting the contribution specific, innovative symbolic technologies have made to the actual constitution of specific ideal objects that Husserl focuses upon in his own discussions. A case in point is the coordinate grid enabling the Cartesian algebraization of geometrical space (see also below) and thus, for the first time, the comprehensive constitution of idealized space as a mathematical object.

This said, there is enough to be found in Husserl's later philosophical writings that allows for making a case for a more positive account, where the genuinely constructive dimensions of symbolic technologies (and of the associated processes of sedimentation) are given their due and potentially beyond what Husserl actually envisioned himself. In particular, and using Husserl's own deliberations as a guide, there are at least two points that can be made for a more positive reading of the role symbolic technologies play in processes of constitution.

\footnotetext{
${ }^{83}$ Husserl (1970a, p. 52).

${ }^{84}$ Rang (1989, p. 120, my translation).

85 Woelert (2012).
} 
The first point to be made concerns the fact that symbolic technologies and the processes of sedimentation that are associated with their use facilitate some sort of liberation of the individual mind and its activity from the ultimately unproductive task of having to constantly think everything anew. This is particular relevant for the domain of scientific thought - any science that was incessantly questioning, and reflecting upon, its own methods and conceptual presuppositions would practically not go anywhere. Indeed, the routinized use of symbolic technologies such as writing - in science and elsewhere - allows for what Husserl already in the Logical Investigations critically refers to as an 'economization of thought', which results in thinking becoming more effortless but also more mechanical and superficial.86 Yet at the same time, it can be reasonably added to Husserl's argumentation that it is precisely through such 'economization' that thinking also attains a degree of freedom from spending too much energy on more mundane cognitive tasks, thus allowing it to build up complexity and become more creative elsewhere - at least potentially. Philip Buckley sums up this point nicely when he remarks that "the ability to use symbols (...) without necessarily making the effort to reactivate the entire process which gave birth to the sign frees thinking to engage in new productive activity" 87 In some sense, Buckley concludes, it can even be said that the more thought is sedimented, the more potential it has to develop further.88

The second point concerns more specifically the role symbolic technologies and processes of sedimentation play in the constitution of ideal objects. In the OG, Husserl repeatedly suggests that there is a crucial link between the use of material, written symbols and that constitution. Husserl stresses in particular that the symbolic technology of writing makes it possible for the "self-evident meaning" of the "original idealities" of geometrical thinking to be "handed down" and (potentially) fully reactivated, thus retaining their "genuine, original meaning." 89 Importantly, however, Husserl also indicates that writing plays a more central role in the constitution of ideal objects than its obvious, conserving function would suggest. Crucial in this context is Husserl's specification that writing facilitates a form of reactivation of these meanings that involves a plurality of human subjects, and to some extent regardless of where and when

\footnotetext{
${ }^{86}$ Husserl (1970c, pp. 197-211).

87 Buckley (1992, p. 91).

${ }^{88}$ Buckley (1992, p. 91).

${ }^{89}$ Husserl (1970b, p. 366). Husserl however never committed to the view that such idealities are themselves originally constituted linguistically. Even in his later thought, Husserl is careful to maintain a distinction between "ideal geometrical objects" - which are understood to be constituted by intentional acts of consciousness - and "the idealities of geometrical words, sentences, theories - considered purely as linguistic structures" (Husserl 1970b, p. 357).
} 
these subjects live - and where in all such reactivation these meanings first of all manifest themselves intersubjectively as remaining always one and the same. ${ }^{90}$ It is precisely this possibility of an intersubjective reactivation that Husserl holds to be crucial for the constitution of ideal objectivity: The "linguistic embodiment make out of the merely intrasubjective structure the objective structure which (...) is in fact present as understandable by all and is valid (....) for all the future." 91 Through writing, the constituted ideal objects are granted a truly supertemporal, "persisting existence" 92 - by virtue of which, it can be inferred, they attain their true form of ideal objectivity (see section 4 for more detail).

In addition to these two points, there is ultimately yet another way in which symbolic technologies can be seen, from a genetic-phenomenological perspective, as being crucial to processes of constitution. While Husserl in his later writings shies away from granting symbolic technologies a genuine, originary constitutive function, such restraint seems questionable if one thinks of more complex varieties of ideal objects. A case in point is the overarching, scientifically operative constitution of geometrical bodies as mathematical entities - a historical achievement that Husserl singles out to be decisive in paving the way for the establishment of the modern sense of rational-scientific thinking. ${ }^{93}$ As illustrated elsewhere, this constitution could never have been achieved by a "pure' thinking'" that would be 'internal' to individual consciousness but only by a thinking that was effectively mediated by symbolic-technological innovations such as the coordinate grid and the symbolic-algebraic equation. ${ }^{94}$ The coordinate grid, in making even complex geometrical properties directly translatable into the linear medium of formalmathematics, effectively facilitates the solving of highly complex geometrical problems by means of the algebraic equation. One can thus agree with Elisabeth Ströker when she observes that, in the instance of the constitution of highly abstract, scientific conceptions of spatial nature, the thinking involved does not merely become "subsequently fixed in a spatial medium" but, from the very outset, "necessarily occurs through signs and only by way of signs." 95

To sum up, in his later writings Husserl comes to recognize that symbolic technologies play a constructive role in processes of constitution by virtue of them retaining the original meaning contents and making them intersubjectively accessible through processes of reactivation.

\footnotetext{
${ }^{90}$ See, e.g., Husserl 1970b, pp. 357-358).

${ }^{91}$ Husserl (1970b, p. 358).

${ }^{22}$ Husserl (1970b, p. 360).

${ }^{93}$ See Husserl (1970a, pp. 43-44).

${ }^{94}$ See Woelert (2012, pp. 357-360).

${ }^{95}$ Ströker (1987, p. 209).
} 
Moreover, and in the particular instance of the constitution of ideal objects, Husserl regards the possibility of such access essential, since it is on the basis of this reactivation that the constituted objects reveal their truly ideal-objective, supertemporal nature. However, one arguable limitation of Husserl's account is his hesitation in seriously considering that symbolic technologies may play a role in the originary constitution of specific ideal objects. 


\section{4) Husserl's account of symbolic technologies: Strengths, weaknesses, and potential}

On the basis of the preceding discussions of Husserl's earlier and later work, one can finally identify a range of strengths and weaknesses characterizing Husserl's philosophical account of symbolic technologies. The weaknesses, it is argued here, articulate themselves in a range of unresolved tensions running through Husserl's deliberations concerning the role symbolic technologies play in processes of constitution.

First, there is a persisting tension in Husserl's writings concerning the relation between those modes of constitution which are understood to have their base in the experiential activity of individual, intentional consciousness, and those modes that involve the use of symbolic and symbolic-technological means. As has been shown, Husserl generally perceives the former mode as primary (since originary) and the latter as secondary. Such delineation and sequencing may make perfect sense from a genetic perspective on meaning-constitution. And as has been shown, it also does not mean that Husserl, and the later Husserl in particular, does not have anything of value to offer when it comes to conceptualizing the constructive role symbolic technologies may play in processes of constitution. This said, and taking into account my preceding discussions (section 3), the point can also be made that Husserl consistently tends to overstate the role that those originary, experience-based modes of constitution play in the original constitution of more abstract intentional objects - most of all that of theoretically complex 'ideal objects' - and to downplay the conceptually constructive role that symbolic technologies may play in this particular context of constitution. Symptomatic in this regard is also Husserl's choice of terms such as 'surrogate', 'extension', 'sedimentation/reactivation', or 'technization' to designate the contribution of symbolic technologies to processes of constitution -terms directly indicating that this contribution is primarily conceived of as secondary as well as being essentially somewhat passive and mechanical.

Second, and on a related note, Husserl's later writings exhibit an unresolved tension with regard to the relation between 'internal' and 'external' history. As discussed, Husserl locates the processes of the constitution, sedimentation and reactivation of meanings strictly within the domain of internal history, which is set apart from the 'external' domain of concrete, factual history. ${ }^{96}$ It is however obvious that such a delineation can hardly be reconciled with Husserl's recognition that the 'external' embodiment of meanings through concrete, material signs is absolutely vital for the accomplishment of the constitution of proper, 'ideal' objectivity. ${ }^{97}$ In

\footnotetext{
${ }^{96}$ See Husserl (1970b, p. 378).

${ }^{97}$ See on this point also Derrida (1978, p. 89).
} 
some sense, it can be argued with Husserl against Husserl, the symbolic technology of writing brings the clear-cut division separating 'internal' from 'factual' history to its implosion. ${ }^{98}$ Of course, one ought not to infer from this that a full-fledged subjugation of internal history to external history would be a conceptually viable alternative. For regardless of the problems stemming from Husserl's strict separation of internal from external history, he is right to assert that an ideal objective formation such as Euclidean geometry - though "having arisen within our human space through human activity"99 - is supertemporal in the sense that its own objectivity extends to everything new which is from then on constructed on its basis. ${ }^{100}$ One may therefore conclude that our ideal-objective formations have a historical dimension in that they have a history of becoming, and, one may add here, have become by way of the assistance of concrete symbolic-technological means. Yet the same formations also operate outside history with regard to their inner 'sense of truth' (Wahrheitssinn).101

The third tension affecting Husserl's philosophical account of symbolic technologies that I want to draw attention to here can be regarded as a particular articulation and continuation of the

98 This tension in Husserl's conception of the relation between internal and external history is reflective of broader tensions implicit to Husserl's mature conception of the life-world, both as concerns the conceptualization of this world's historicity as well as this world's relation to the world of technology. With regard to the former aspect, Husserl's notion of the life-world contains an unresolved tension in his attempt to posit the life-world as a universal "meaning-fundament" (Husserl 1970a, p. 49), while at the same time conceptually approaching the life-world in terms of its being a concrete historical world. The dilemma is obvious, as noted by Waldenfels: If the life-world (and every possible life-world) is indeed by its very nature concrete-historical, then this world can hardly be granted the function of a universal fundament or foundation; and if this world is granted precisely this function, then it can hardly be conceived of as being concrete historical (1985, p. 20). With regard to Husserl's conceptualization of the relation between the life-world and the world of technology, one can observe a related issue stemming from Husserl's tendency to posit the life-world as an originary sphere of 'pure' experience existing 'prior' to technological intervention. As pointed out by Blumenberg (1981, pp. 24-26), this stance of Husserl's is already problematic in that the life-world thus construed is in truth already a methodological (and in this sense already 'technical') product of a process of abstraction away from the way human agents concretely experience their world. For as a matter of fact, and as stressed by various commentators (e.g., Claesges 1972; Blumenberg, 1981; Murata 1987), any historical human life-world, and most of all our contemporary life-world is never just constituted as a world of 'pure' experience but also always already as a technical world, with technical artifacts being an intrinsic part of this world and the ways it is experienced (Claesges, 1972, p. 90).

${ }^{99}$ Husserl (1970b, p. 355).

${ }^{100}$ Husserl (1970b, p. 356).

${ }^{101}$ See Husserl (1993, p. 173). 
first tension referred to above. It also relates to the second tension just identified. This third tension is related to Husserl's wavering in his theory of constitution between a position in which the individual is prioritized and a position in which the communal, intersubjective dimensions of processes of constitution are prioritized. The complex tensions between Husserl's 'solipsist' and 'intersubjective' tendencies have been well rehearsed. ${ }^{102}$ At times, Husserl tends to regard the ego as the center and sole source of all constitutive accomplishments; yet at other times, Husserl departs from such a position to embrace the notion of a constituting " $[t]$ ranscendental intersubjectivity (...) out of which", he insists, "everything objective (the totality of objectively real entities, but also every objective ideal world) draws its sense and validity."103 Given the latter statement, it is not surprising that Husserl (at least in the OG) emphasizes the expansion of intersubjective relations that writing facilitates and the bearing that this has on the constitution of ideal objectivity. In doing so, Husserl even moves to a position that suggests that it is writing itself that ultimately bestows ideal objects with their true, or, as Klein puts it, "perfect 'objectivity'."104 Yet at the same time Husserl apparently also maintains, even in the OG, that the ultimate and founding source for the constitution of ideal objects is individual consciousness and its intentionality. ${ }^{105}$ The apparent tension between both positions is not fully explicated and ultimately remains unresolved in Husserl's genetic writings.

Apart from these unresolved tensions, however, Husserl's conception of symbolic technologies has to be lauded for broadly anticipating the move beyond a limiting philosophical perspective that considers the respective domains of technology and rational thought on strictly separate terms. More importantly, it can also be argued that his more mature, genetic conceptions in particular are enduringly instructive to understand some of the more critical implications current symbolic-technological shifts may have for our cognitive lives and our own, cognitive agency.

With regard to the first point, it is important to note that the early Husserl's conception of symbolic technologies was clearly ahead of its time in moving beyond a philosophical view that either ignores the crucial role that technological artifacts play in the constitution of specific domains of human thinking, or which frames this role in terms of these artifacts' putative epistemic neutrality. The crux of the matter in this context is the early Husserl's recognition that

\footnotetext{
${ }^{102}$ See, e.g., Zahavi (2003, pp. 109-125); Zahavi (2001).

103 Husserl (1968, p. 344; see also Husserl 1960, p. 30). The translation above follows that provided by Zahavi (2003, pp. 110-111).

104 Klein (1940, p. 155; see similarly Derrida 1978, p. 87).

105 See Husserl (1970b, pp. 357-358).
} 
in more abstract domains of rational-mathematical thought, the use of symbolic technologies is not a mere addendum but is intrinsically linked to the unfolding of such thought's inner logic 106 - in some sense, it could even be considered to be formative of such thought in the first place. ${ }^{107}$

With regard to the second point, the key idea is Husserl's conceptualization of the often unnoticed and unintended epistemic consequences that the use of symbolic technologies may have, above all in the domain of formal-rational thinking. Conceptually subsumed under the concept of 'technization', Husserl's core insight could be summed up as follows: The more we gain from our symbolic technologies, which alleviate and increasingly shape our rational thinking, the more we also become prone to using them and their products in a superficial, 'thoughtless' manner. This insight maintains its purchase in our contemporary times, regardless of all the limitations in Husserl's recognition of the creative and indeed constitutive dimensions of symbolic technologies, and regardless also of the ever more dramatic technological advances in the domain of artifacts such as modern computers capable of highly complex symbolprocessing operations.

Our contemporary computers facilitate a degree of calculability and economy in rational thinking formerly unthinkable, and mediate and permeate our thinking to an extent that is unprecedented in history. Yet at the same time, the operation of the same devices has also become relatively easy and effortless, at least if compared to the demands that are associated with the use of the traditional, manual 'method of sensible signs' - for in the instance of computers, both the processes of the manipulation of symbols as well as the associated computations are now largely externalized, and generally remain hidden from the view of the human operators. Indeed, in most instances, these operators do not even need to possess a firm grasp of the "formula-meaning"'108 that is required for the use of the 'method of sensible signs' to reliably produce results. It could therefore be argued that in the use of such powerful symbolic technologies the risk of occurrences of technization has likewise increased, and it will further increase the more powerful and the more easily manageable our symbolic technologies become.

In view of these technological developments and their potential repercussions, it can ultimately be said that the task of carefully identifying and analyzing processes of technization and their effects in various domains of human life may be more imperative than ever before in history. In order to engage in this task more effectively, not only a better understanding of Husserl's work

\footnotetext{
106 Husserl (2003, p. 272).

107 Husserl (2003, p. 200; also p. 255).

108 Husserl (1970a, p. 33).
} 
in contemporary philosophy of technology and other relevant fields will be needed, but ultimately also a more outward-looking approach among those working within the tradition of Husserlian phenomenology. 


\section{References}

Bernet, R., Kern, I. and Marbach, E. (1993). An introduction to Husserlian phenomenology. Evanston, Ill.: Northwestern University Press. (Original work published 1989).

Blumenberg, H. (1981). Lebenswelt und Technisierung unter Aspekten der Phänomenologie. In Hans Blumenberg, Wirklichkeiten, in denen wir leben (pp. 7-54). Stuttgart: Reclam. (Original work published in 1963).

Buckley, P. (1992). Husserl, Heidegger, and the crisis of philosophical responsibility. Dordrecht: Kluwer.

Clark, A., \& Chalmers, D. (1998). The extended mind. Analysis 58(1): 7-19.

Clark, A. (2008). Supersizing the mind: Embodiment, action, and cognitive extension. Oxford: Oxford University Press.

Claesges, U. (1972). Zweideutigkeiten in Husserls Lebenswelt-Begriff. In U. Claesges \& K. Held (Eds.), Perspektiven transzendentalphänomenologischer Forschung (pp. 85-101). The Hague: Martinus Nijhoff.

Da Silva, J. J. 2010. Beyond Leibniz: Husserl's vindication of symbolic knowledge. In M. Hartimo (Ed.), Phenomenology and Mathematics (pp. 123-145). Dordrecht: Springer.

Derrida, J. (1978). Edmund Husserl's Origin of Geometry: An introduction (J. P. Leavey, Trans.). Stony Brook, N.Y.: N. Hays. (Original work published in 1962).

Donald, M. (2010). The exographic revolution: Neuropsychological sequelae. In L. Malafouris \& C. Renfrew (Eds.), The cognitive life of things: Recasting the boundaries of the mind (pp. 71-79). Cambridge, UK: McDonald Institute for Archaeological Research.

Duke, G., \& Woelert, P. (2016). Husserl and the problem of abstract problems. Pacific Philosophical Quarterly, 97(1): 27-47.

Floridi, L. (2014). The fourth revolution: How the infosphere is reshaping human reality. Oxford: Oxford University Press.

Hartimo, M. J. (2012). Husserl's pluralist phenomenology of mathematics. Philosophica Mathematica, 20, 86-110.

Heersmink, R. (2013). A taxonomy of cognitive artifacts: Function, information, and categories. Review of Philosophy and Psychology, 4(3): 465-481.

Hopkins, B. (2002a). Authentic and symbolic numbers in Husserl's Philosophy of Arithmetic. The New Yearbook for Phenomenology and Phenomenological Philosophy II: 39-71.

Hopkins, B. (2011). The origin of the logic of symbolic mathematics: Edmund Husserl and Jacob Klein. Bloomington, Ind.: Indiana University Press. 
Husserl, E. (1960). Cartesian Meditations: An introduction to phenomenology (D. Cairns, Trans.). The Hague: Martinus Nijhoff. (Original work published 1931).

Husserl, E. (1968). Phänomenologische Psychologie. Vorlesungen Sommersemester 1925. Husserliana IX ( $2^{\text {nd }}$ ed., W. Biemel, Ed.). The Hague: Martinus Nijhoff.

Husserl, E. (1969). Formal and transcendental logic (D. Cairns, Trans.). The Hague: Martinus Nijhoff. (Original work published 1929).

Husserl, E. (1970a). The crisis of European sciences and transcendental phenomenology: An introduction to phenomenological philosophy (D. Carr, Trans.). Evanston, Ill.: Northwestern University Press. (Original work published 1954).

Husserl, E. (1970b). The origin of geometry (D. Carr, Trans.). In Edmund Husserl, The crisis of European sciences and transcendental phenomenology: An introduction to phenomenological philosophy (pp. 353378). Evanston, Ill.: Northwestern University Press. Originally published in 1939.

Husserl, E. (1970c). Logical investigations (2 Vol.) (J. M. Findlay, Trans.). London: Routledge \& Kegan Paul. (Original work published 1900 (1 $\left.{ }^{\text {st }}\right)$ and 1913 (2nd rev).

Husserl, E. (1970d). Philosophie der Arithmetik. Mit ergänzenden Texten (1890-1901). Husserliana XII (L. Eley, Ed.). The Hague, Martinus Nijhoff.

Husserl, E. (1982). Ideas pertaining to a pure phenomenology and to a phenomenological philosophy. First book: General introduction to a pure phenomenology (F. Kerstens, Trans.). Dordrecht: Kluwer. (Original work published 1913).

Husserl, E. (1993). Die Krisis der europäischen Wissenschaften und die transzendentale Phänomenologie. Ergänzungsband Texte aus dem Nachlass 1934-1937 (R. N. Smid, Ed). Dordrecht: Kluwer.

Husserl, E. (2003). Philosophy of arithmetic: Psychological and logical investigations with supplementary texts from 1887-1901 (D. Willard, Trans.). Dordrecht: Kluwer. (Original work published 1891).

Hutchins, E. (2001). Cognitive artifact. In R. A. Wilson \& F. C. Keil (Eds.), The MIT encyclopedia of the cognitive sciences (pp. 126-128). Cambridge, MA: MIT Press.

Ierna, C. (2003). Husserl and the infinite. Studia Phaenomenologica, 3(1-2): 179-194.

Kelly, M. (2005). Making a case for Husserl in the philosophy of technology. Philosophy Today, 49(3): 225235.

Klein, J. (1940). Phenomenology and the history of science. In M. Farber (Ed.), Philosophical essays in memory of Edmund Husserl (pp. 143-163). Cambridge, MA: Harvard University Press.

Klein, J. (1968). Greek mathematical thought and the origin of algebra (E. Brann, Trans.). Cambridge, MA: MIT Press. (Original work published 1934 and 1936). 
Krämer, S. (1988). Symbolische Maschinen. Die Idee der Formalisierung in geschichtlichem Abriß.

Darmstadt: Wissenschaftliche Buchgesellschaft.

Menary, R. (2007). Cognitive integration: Mind and cognition unbounded. Basingstoke: Palgrave MacMillan.

Miller, J. P. (1982). Numbers in presence and absence: A study of Husserl's philosophy of mathematics.

Dordrecht: Kluwer.

Murata, J. (1987). Wissenschaft, Technik, Lebenswelt. Husserl Studies 4(3): 193-208.

Rang, B. (1989). Die bodenlose Wissenschaft. Husserls Kritik von Objektivismus und Technizismus in Mathematik und Naturwissenschaft. Phänomenologische Forschungen 22: 88-136.

Rowlands. M. (1999). The body in mind: Understanding cognitive processes. Cambridge: Cambridge University Press.

Sokolowski, R. (1964). The formation of Husserl's concept of constitution. The Hague: Nijhoff.

Ströker, E. (1993). Husserl's transcendental phenomenology (L. Hardy, Trans.). Stanford: Stanford University Press. (Original work published in 1987).

Ströker, E. (1987). Investigations in philosophy of space (A. Mickunas, Trans). Athens, Ohio: Ohio University Press. (Original work published in 1965).

Tieszen, R. L. (1989). Mathematical intuition: Phenomenology and mathematical knowledge. Dordrecht: Kluwer.

Tieszen, R. L. (2005). Phenomenology, logic, and the philosophy of mathematics. Cambridge: Cambridge University Press.

Tieszen, R. L. (2010). Mathematical realism and transcendental phenomenological idealism. In M. Hartimo (Ed.) Phenomenology and mathematics (pp. 1-22). Dordrecht: Springer.

Waldenfels, B. (1985). In den Netzen der Lebenwelt. Frankfurt/Main: Suhrkamp.

Wheeler, M. (2005). Reconstructing the cognitive world. Cambridge, MA: MIT Press.

Willard, D. (1984). Logic and the objectivity of knowledge: A study in Husserl's early philosophy. Athens, Ohio: Ohio University Press.

Woelert, P. (2011). Human cognition, space, and the sedimentation of meaning. Phenomenology and the Cognitive Sciences, 10(1): 113-137.

Woelert, P. (2012). Idealization and external symbolic storage: The epistemic and technical dimensions of theoretic cognition. Phenomenology and the Cognitive Sciences, 11(3): 335-366. 
Woelert, P. (2013). Technology, knowledge, governance: The political relevance of Husserl's critique of the epistemic effects of formalization. Continental Philosophy Review, 46(4): 487-507.

Zahavi, D. (2001). Husserl and transcendental intersubjectivity: A response to the linguistic-pragmatic critique. Ohio: Ohio University Press.

Zahavi, D. (2003). Husserl's phenomenology. Stanford: Stanford University Press. 


\section{University Library}

\section{- M M I N E R VA A gateway to Melbourne's research publications}

Minerva Access is the Institutional Repository of The University of Melbourne

Author/s:

Woelert, $P$

Title:

Husserl on symbolic technologies and meaning-constitution: A critical inquiry

Date:

2017-09-01

Citation:

Woelert, P. (2017). Husserl on symbolic technologies and meaning-constitution: A critical inquiry. CONTINENTAL PHILOSOPHY REVIEW, 50 (3), pp.289-310. https://doi.org/10.1007/ s11007-016-9408-y.

Persistent Link:

http://hdl.handle.net/11343/282992 